\title{
Effect of 3-aminobenzamide on chromosome damage in human blood lymphocytes adapted to bleomycin
}

\author{
Vijayalaxmi ${ }^{1}$ and W.Burkart \\ Radiation Biology Unit, Paul Scherrer Institute, CH-5303 Wurenlingen, \\ Switzerland \\ 'To whom correspondence should be addressed
}

Human blood lymphocytes, pre-treated with very low (adaptation) concentrations of bleomycin for $48 \mathrm{~h}$ and then exposed to a high (challenge) dose of the same agent or $X$-rays, became significantly less sensitive to the induction of chromosome damage than those which did not receive the pre-treatment, indicating an induction of 'adaptive repair' process. This repair process was negated when 3-aminobenzamide, an inhibitor of poly (ADP) polymerase, was added to the cultures immediately after the challenge treatment. The magnitude of negation in the adaptation response was greater in the case of lymphocytes challenged with $\mathrm{X}$-rays as compared with those challenged with bleomycin.

\section{Introduction}

There is growing evidence for the existence of an adaptive response in human blood lymphocytes, similar to that found in Escherichia coli (Samson and Cairns, 1977) and rodent cells (Samson and Schwartz, 1980). Olivieri et al. (1984) first reported that prior exposure of human lymphocytes to low levels of radioactive thymidine $\left({ }^{3}[\mathrm{H}] \mathrm{dThd}\right)$ led to a significant reduction in the chromosome damage induced by a subsequent high dose of X-rays. Shadley and Wolff (1987) also observed that an X-ray dose, as low as $0.01 \mathrm{~Gy}$, can protect the lymphocytes against the cytogenetic damage induced by a subsequent exposure to 1.5 Gy X-rays. The radiation dose used for adaptation seemed to have an effect; so also the time-interval between the adaptation and challenge doses (Shadley et al., 1987), the dose rate and the quality of radiation (Wiencke et al., 1987). Sankaranarayanan et al. (1989) have confirmed the original results of Olivieri et al. (1984). More recently, Wolff et al. (1988) reported that human blood lymphocytes adapted to low doses of ionizing radiation became refractory to chromosome damage, not only by a high dose of radiation but also by chemical mutagens that induce similar kinds of lesions in DNA.

Bleomycin (BLM) is an anti-tumour antibiotic drug, widely used in the treatment of a variety of human malignancies (Bonadonna et al., 1972). Its action on DNA and chromosomes has been shown to be similar to that of ionizing radiation (Tamura et al., 1974; Dresp et al., 1978). These similarities prompted us to investigate whether or not an adaptation response can be elicited by BLM in human blood lymphocytes. We observed that prior exposure of the lymphocytes to low doses of BLM made them significantly less sensitive to the induction of chromosome damage by subsequent exposure to a high dose of not only BLM but also X-rays (Vijayalaxmi and Burkart, 1989). These results lend further support to the operation of an adaptive repair process in human lymphocytes which offers resistance and crossresistance to chromosome damage by the same or similar DNA damaging agents.
All these studies point to an inducible resistance to DNA damage and the possible role of the enzymes involved in the repair of damaged DNA. The activity of poly (ADP-ribose) polymerase (Skidmore et al., 1979; Durkacz et al., 1980) has been implicated in lymphocytes adapted to ${ }^{3}[\mathrm{H}] \mathrm{dThd}$ and X-rays (Wiencke $e t$ al., 1986; Shadley et al., 1987). A similar study has been conducted to examine the role of 3-aminobenzamide (3AB), a potent inhibitor of poly (ADP-ribose) polymerase, on the chromosome damage in human blood lymphocytes adapted to BLM. The results are reported here.

\section{Materials and methods}

Heparinized blood samples were obtained from two healthy, non-smoking females, aged between 25 and 30 years. From each sample, separate cultures were set up using $1 \mathrm{ml}$ blood in $10 \mathrm{ml}$ RPMI 1640 medium containing $15 \%$ fetal calf serum, $1 \%$ PHA (Gibco), $1 \%$ glutamine, $10 \mathrm{U} / \mathrm{ml}$ penicillin, $10 \mu \mathrm{g} / \mathrm{ml}$ streptomycin and kept at $37^{\circ} \mathrm{C}$ in $5 \%$ carbon dioxide incubator. Four hours later, the adaptation doses of BLM (Lundbeck, Denmark), freshly prepared in sterile distilled water, were added to give final concentrations of 0.01 and $0.05 \mu \mathrm{g} / \mathrm{ml}$ and the cultures returned to the incubator. At $48 \mathrm{~h}$, the cells were exposed to a challenge dose of $1.5 \mu \mathrm{g} / \mathrm{ml}$ BLM or 1.5 Gy X-rays (Philips X-ray machine, model MCN 321 , $240 \mathrm{kV}, 7 \mathrm{~mA}, 1-\mathrm{mm}$ aluminium filter; cultures were kept at a distance of $50 \mathrm{~cm}$ from the radiation source and the dose rate of $1.5 \mathrm{~Gy}$ was checked using Farmer dosemeter 2570). 3AB (Sigma), freshly made up in medium to give a final concentration of $2 \mathrm{mM}$, was added immediately after the challenge dose. The incubation continued for a further period of $6 \mathrm{~h}$. For the last $2 \mathrm{~h}$, the cells were also treated with $1 \mu \mathrm{g} / \mathrm{ml}$ colcemid (Gibco). Lymphocytes were collected, treated with $75 \mathrm{mM}$ potassium chloride for $7 \mathrm{~min}$ and then fixed in 3:1 methanol:acetic acid mixture. Fixed cells were dropped onto clean slides, air-dried and stained with Giemsa. Coded slides'were examined for chromosome damage. Two-hundred metaphases were analysed from each culture. Gaps and achromatic lesions less than the width of a chromatid were not included in the scoring. Very few chromatid exchanges and dicentric chromosomes were recorded but not included in the analysis. The data on the inciderice of chromatid and isochromatid breaks (observed versus expected) were subjected to statistical analysis using one-tailed $t$-test.

\section{Results and discussion}

The overall response of the lymphocytes from two blood samples studied is similar and the pooled data on chromosome (chromatid + isochromatid) breaks are given in Table I. As can be seen, the adaptation doses of 0.01 and $0.05 \mu \mathrm{g} / \mathrm{ml} \mathrm{BLM}$ induces a small increase $(2-5 \%)$ in the frequency of chromosome breaks, whereas the challenge dose of $1.5 \mu \mathrm{g} / \mathrm{ml} \mathrm{BLM}$ alone, given $6 \mathrm{~h}$ before fixing the cells, induces a significant number of chromosome breaks $(65 \%)$. In lymphocytes which received both adaptation and challenge doses of BLM, the incidence of chromosome breaks is significantly lower than those expected on the basis of additive effects of two individual treatments. The reduction observed with the adaptation doses of 0.01 and $0.05 \mu \mathrm{g} / \mathrm{ml} \mathrm{BLM}$ is 61 and $54 \%$ respectively. The challenge dose of $1.5 \mathrm{~Gy} \mathrm{X}$-rays alone, given to the lymphocytes $6 \mathrm{~h}$ before fixation, induces $30 \%$ chromosome breaks. When the cells adapted to BLM are subsequently challenged with $1.5 \mathrm{~Gy}$ X-rays, the yield of chromosome breaks is significantly lower than the sum of the effects induced by two treatments separately. The reduction observed with the adaptation doses of 0.01 and $0.05 \mu \mathrm{g} / \mathrm{ml} \mathrm{BLM}$ is 59 and $52 \%$, respectively. These data confirm the results of our previous experiments (Vijayalaxmi and 


\begin{tabular}{|c|c|c|c|c|c|c|}
\hline- & - & 3 & 1 & 4 & & \\
\hline- & $3 \mathrm{AB}$ & 3 & 1 & 4 & & \\
\hline- & BLM & 124 & 136 & 260 & & \\
\hline 0.05 & - & 10 & 12 & 22 & & \\
\hline 0.01 & BLM & 50 & 53 & $103^{a}$ & 265 & 61 \\
\hline 0.01 & $\mathrm{BLM}+3 \mathrm{AB}$ & 91 & 107 & $198^{b}$ & 265 & 25 \\
\hline 0.05 & BLM & 55 & 72 & $127^{2}$ & 278 & 54 \\
\hline 0.05 & $\mathrm{BLM}+3 \mathrm{AB}$ & 99 & 111 & $210^{b}$ & 278 & 24 \\
\hline 0.01 & $\mathrm{X}$-rays & 26 & 28 & $54^{a}$ & 131 & 59 \\
\hline
\end{tabular}

The treatment schedule is described in Materials and methods. Expected values are the sum of two individual treatments minus the control. Difference between observed and expected values:

${ }^{\mathrm{a} P}<<0.001 ;{ }^{\mathrm{b}} P<0.025 ;{ }^{\mathrm{c}}$ not significant.

Difference between $\pm 3 \mathrm{AB}$ cultures: $P<0.001$.

Burkart, 1989) and are in agreement with other published reports on the induction of adaptation response in human blood lymphocytes.

The data presented in Table I also indicate that the addition of $3 \mathrm{AB}$ alone, $6 \mathrm{~h}$ before fixing the lymphocytes, has no effect on the frequency of chromosome breaks over the control value. When $3 \mathrm{AB}$ is added to the adapted lymphocytes, immediately after the challenge treatment with $1.5 \mu \mathrm{g} / \mathrm{ml} \mathrm{BLM}$, the reduction in the incidence of chromosome damage is $25-24 \%$, as compared with $61-54 \%$ (without $3 \mathrm{AB}$ treatment). A similar difference, with and without $3 \mathrm{AB}$ treatment, is also observed in the case of challenge with 1.5 Gy X-rays: $15-14 \%$ as compared with $59-52 \%$. These results suggest that the addition of $3 \mathrm{AB}$ negates the adaptation response in human lymphocytes and support the observations made by Wiencke et al. (1986) and Shadley et al. (1987). However, the magnitude of reduction in the adaptation response by $3 \mathrm{AB}$ is greater in the case of challenge with $\mathrm{X}$-rays as compared with BLM.

Chinese hamster ovary cells treated with BLM have been shown to synthesize poly (ADP-ribose) in a reaction which is dose- and time-dependent and the addition of inhibitors like $3 \mathrm{AB}$ inhibited this reaction resulting in increased cell killing (Huet and Laval, 1985) and chromosome damage (Zwanenburg et al., 1985). Enhancement of anti-tumour activity of BLM by inhibitors of poly (ADP-ribose) polymerase has also been demonstrated in vivo and in vitro (Kawamitsu et al., 1982; Sakamoto et al., 1983). These reports are interesting in the context of the present study and implicate that poly (ADP-ribose) polymerase is involved not only in the repair of BLM-induced DNA damage but also in negating the adaptation response in human lymphocytes. It would be interesting to study the effect of $3 A B$ on the rate of poly (ADP-ribose) synthesis and DNA repair kinetics in BLM-adapted lymphocytes.

The magnitude of negation in the adaptation response is greater in the case of challenge with $1.5 \mathrm{~Gy} \mathrm{X}$-rays as compared with $1.5 \mu \mathrm{g} / \mathrm{ml}$ BLM. It may be relevant to refer to the data which suggest that BLM is inactivated by an enzyme, BLM-hydroxylase (Umezawa, 1973) and that the therapeutic effects of BLM could be related to the distribution of BLM-hydroxylase in the tissues
(Ichikawa, 1969; Clinical screening group of EORTC, 1970). Transplantable tumour cell lines which have higher BLMhydroxylase are shown to be comparatively more resistant to BLM (Yoshioka et al., 1978). Whether the adaptation doses of BLM stimulate the activity of BLM-hydroxylase, which offers the cells an increased resistance to BLM challenge dose, and whether the enzyme also plays a role in negating the adaptation response is not known. Experiments are in progress along these lines.

BLM is widely used as a therapeutic agent for a variety of human cancers; depending upon the fractionation of the doses employed and the duration of treatment, the possibility of an adaptation response of the tumour tissues/cells should be carefully assessed. Recently, Sakamoto et al. (1983) have demonstrated that daily treatment with various doses of BLM + benzamide, given to mice with Ehrlich ascites tumours, has increased the survival of the animals as compared with those mice on treatment with BLM alone. The usefulness of the administration of inhibitors of poly (ADP-ribose) polymerase/BLM-hydroxylase along with BLM in the treatment of human cancers remains to be elucidated.

\section{Acknowledgements}

We thank Mrs L.Gross for help in irradiating the blood samples.

\section{References}

Bonadonna,G., DeLena,M., Monfardini,S., Bartoli,C., Bajetta,E., Baretta,G. and Fossati-Bellani,F. (1972) Clinical trials with bleomycin in lymphomas and in solid tumors. Eur. J. Cancer, 8, 205-215.

Clinical screening cooperative group of the European Organization for Research on the Treatment of Cancer: study of the clinical efficiency of bleomycin in human cancer (1970) Br. Med. J., 2, 643-645.

Dresp,J., Schmid,E. and Bauchinger,M. (1978) The cytogenetic effect of bleomycin on human peripheral lymphocytes in vitro and in vivo. Mutal. Res., 56, 341-353.

Durkacz,B.W., Omidiji,O., Gray,D.A. and Shall,S. (1980) (ADP-ribose) participates in DNA excision repair. Nature, 283, 593-596.

Huet,J. and Laval,F. (1985) Potentiation of cell killing by inhibitors of poly (adenosine diphosphate-ribose) synthesis in bleomycin-treated Chinese hamster ovary cells. Cancer Res., 45, 987-991.

Ichikawa, T. (1969) Bleomycin, a new antitumor antibotic, as a specific against the squamous cell carcinoma. J. Jap. Med. Assoc., 61, 487-497. 
Kawamitsu,H., Miwa,M., Tanaka,Y., Sakamoto,H., Terada,M., Hoshi,A. and Sugimura, T. (1982) Inhibitors of poly(adenosine diphosphate ribose) polymerase potentiate the antitumor activity of bleomycin against Ehrlich ascites carcinoma. J. Parm. Dyn., 5, 900-904.

Olivieri,G., Bodycote,J. and Wolff,S. (1984) Adaptive response of human lymphocytes to low concentrations of radioactive thymidine. Science, 223, $594-597$.

Sakamoto,H., Kawamitsu,H., Miwa,M., Terada,M. and Sugimura,T. (1983) Enhancement of antitumor activity of bleomycin by benzamide in vitro and in vivo. J. Antibiot., 36, 296-300.

Samson,L. and Cairns,J. (1977) A new pathway for DNA repair in Escherichia coli. Nature, 267, 281-283.

Samson,L. and Schwartz,J.L. (1980) Evidence for an adaptive DNA repair pathway in CHO and human skin fibroblast cell lines. Nature, 287, 861-863.

Sankaranarayanan,K., Duyn,A.v., Loos,M.J. and Natarajan,A.T. (1989) Adaptive response of human lymphocytes to low concentrations of radio-isotopes. Mutat. Res., in press.

Shadley,J.D. and Wolff,S. (1987) Very low doses of X-rays can cause human lymphocytes to become less susceptible to ionizing radiation. Mutagenesis, 2 , 95-96.

Shadley,J.D., Afzal,V. and Wolff,S. (1987) Characterization of the adaptive response to ionizing radiation induced by low doses of $\mathrm{X}$-rays to human lymphocytes. Radiat. Res., 111, 511-517.

Skidmore,C.J., Davies,M.I., Goodwin,P.M., Halldorsson,H., Lewis,P.J., Shall,S. and Zia'ce,A. (1979) The involvement of poly (ADP-ribose) polymerase in the degradation of NAD caused by $r$-irradiation and $N$-methyl- $N$-nitrosourea. Eur. J. Biochem., 101, 135-142.

Tamura,H., Sugiyama,Y. and Sugahara,T. (1974) Effect of bleomycin on the chromosomes of human lymphocytes at various cell phases. Gann, 65, $103-107$.

Umezawa,H. (1973) Studies on bleomycin: chemistry and the biological action. Biomedicine, 18, 459-475.

Vijayalaxmi and Burkart,W. (1989) Resistance and cross-resistance to chromosome damage in human blood lymphocytes adapted to bleomycin. Mutat. Res., in press.

Wiencke,J.A., Afzal,V., Olivieri,G. and Wolff,S. (1986) Evidence that the $\left[{ }^{3} \mathrm{H}\right]$ thymidine-induced adaptive response of human lymphocytes to subsequent doses of X-rays involves the induction of a chromosomal repair mechanism. Mutagenesis, 1, 375-380.

Wiencke,J.A., Shadley,J.D., Kelsey,K.T., Kronenberg,A. and Little,J.B. (1987) Failure of high intensity $X$-ray treatments or densely ionizing fast neutrons to induce the adaptive response in human lymphocytes. In Fielden,E.M., Fowler,J.F., Hendry,J.H. and Scott,D. (eds), Proc. VIII Internat. Cong. Radiat. Res., Edinburgh, July 19-24. Taylor and Francis, London, vol. 1, p. 212.

Wolff,S., Afzal,V., Wiencke,J.K., Olivieri,G. and Michael,A. (1988) Human lymphocytes exposed to low doses of ionizing radiations become refractory to high doses of radiation as well as to chemical mutagens that induce doublestrand breaks in DNA. Int. J. Radiat. Biol., 53, 39-48.

Yoshioka,O., Amano,N., Takahashi,K., Matsuda,A. and Umezawa,H. (1978) Intracellular fate and activity of bleomycin. In Carter,S.K., Crooke,S.T. and Umezawa,H. (eds), Bleomycin. Current Status and New Developments. Academic Press, New York, pp. 35-56.

Zwanenburg,T.S.B., Hansson,K., Darroudi,F., van Zeeland,A.A. and Natarajan, A.T. (1985) Effects of 3-aminobenzamide on Chinese hamster cells treated with thymidine analogues and DNA-damaging agents. Chromosomal aberrations, mutations and cell-cycle progression. Mutat. Res., 151, 251-262.

Received on August 1, 1988; accepted on October 28, 1988 